\title{
Roux En Y drainage of a large hepatic hydatid cyst as treatment for recalcitrant bile leak: a case report
}

\author{
Saswati Behera', Monika Bawa ${ }^{1 *}$, Ravi P. Kanojia ${ }^{1}$, Ashwani Sood ${ }^{2}$ and Ram Samujh ${ }^{1}$
}

\begin{abstract}
Background: Hydatid disease is relatively uncommon in children and thus rarely reported in literature. Pediatric patients with large hydatid cysts can have grave complications due to mass effect. Postoperative bile leak is the most common morbidity and continues to be a challenge for the treating surgeon.

Case presentation: A 7-year-old boy diagnosed with a giant hydatid cyst of the liver, almost replacing the right lobe, and underwent a laparotomy and excision of cyst with tube drainage. He developed postoperative major bile leak which did not subside even after a redo laparotomy and closure of the suspected bile leak areas. The child underwent a third laparotomy after a hepatobiliary scintigraphy (HIDA scan) which confirmed a persisting major leak. A Roux En Y cystojejunostomy was done this time which drained the bile adequately postoperatively with no evidence of bile in the subhepatic drain. Oral feeds were resumed on the fifth postoperative day. He was discharged in a satisfactory condition and is doing well in the follow-up. Repeat HIDA scan showed no evidence of spillage, with adequate bilio-enteric drainage.
\end{abstract}

Conclusion: Persistent major bile leak requiring ERCP with sphincterotomy can be managed successfully in children by internal drainage as Roux En Y cystojejunostomy.

Keywords: Giant hydatid cyst, Pediatric, Postoperative bile leak, HIDA scan, Cystojejunostomy

\section{Background}

Pediatric giant hydatid cysts are rare and can have grave complications due to mass effect. Treatment options depend on the size, location, and symptomatology, thus range from marsupialization to hepatectomy. Sudden decompression of giant cyst during drainage causes reversal of pressure dynamics and bile flow into the residual cavity rather than into the bilio-enteric path through ampulla of Vater [1]. Thus, postoperative biliary fistula is the most common morbidity accounting from 13 to $30 \%$ incidence in children which poses a challenge to the treating surgeon [2].

\footnotetext{
* Correspondence: monikabawa@hotmail.com

${ }^{1}$ Department of Pediatric Surgery, Post Graduate Institute of Medical Education and Research (PGIMER), Sector 12, Chandigarh 160012, India Full list of author information is available at the end of the article
}

We, hereby, report a major postoperative bile leak in a 7-year-old child with a large liver hydatid cyst, managed successfully with a cysto-jejunostomy.

\section{Case presentation}

A 7-year-old boy presented with sudden onset severe pain in the right hypochondrium, associated with multiple episodes of non-bilious copious vomiting. He was referred from a primary health care center as a suspected case of hepatic malignancy. There was no past history of similar episodes of pain.

On examination, the liver was enlarged and tender with liver dullness up to $6 \mathrm{~cm}$ below the right costal margin. Ultrasound revealed hepatomegaly along with a large cystic lesion of $10 \times 9 \times 9 \mathrm{~cm}$ involving segments VI, VII, and VIII of the liver and these findings were confirmed with a pre-operative contrast enhanced

\section{Springer Open}

(c) The Author(s). 2020 Open Access This article is licensed under a Creative Commons Attribution 4.0 International License, which permits use, sharing, adaptation, distribution and reproduction in any medium or format, as long as you give appropriate credit to the original author(s) and the source, provide a link to the Creative Commons licence, and indicate if changes were made. The images or other third party material in this article are included in the article's Creative Commons licence, unless indicated otherwise in a credit line to the material. If material is not included in the article's Creative Commons licence and your intended use is not permitted by statutory regulation or exceeds the permitted use, you will need to obtain permission directly from the copyright holder. To view a copy of this licence, visit http://creativecommons.org/licenses/by/4.0/. 

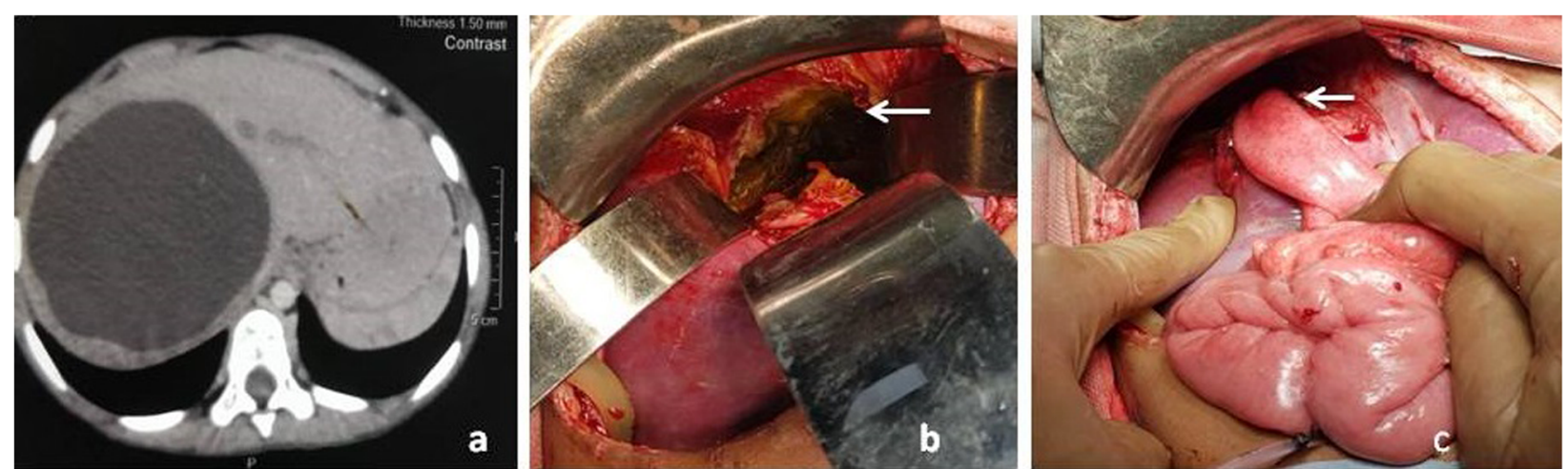

Fig. 1 CECT abdomen - large thin walled, homogeneous cystic lesion, completely replacing segments VI, VII, and VIII, with no contrast enhancement (a). On re-exploration, sub-hepatic collection was drained and the cyst cavity was opened up. No active bile seepage noted and thorough lavage given (b). Roux limb: $40 \mathrm{~cm}$ distal to duodeno-jejunal flexure, jejunal loop divided, and mobilized through the transverse mesocolon up to the cystic cavity. The mobilized jejunal limb sutured (cysto-jejunostomy) to the cystic margin (single-layered, hand sewn, interrupted) using vicryl 4-0 (c)

computed tomography (CECT) abdomen (Fig. 1a). Chest $\mathrm{X}$-ray was done to rule out any associated lung cyst. The hydatid IgG serology was elevated $(8.99 \mathrm{IU} / \mathrm{ml})$. Liver function tests (LFT) showed elevated enzymes with normal bilirubin levels. The child was resuscitated with fluids and antibiotics to correct dehydration and dyselectrolytemia. A preoperative course of albendazole was given for 25 days in lieu of the large size of the cyst. On laparotomy with a right-side subcostal incision, under general anesthesia and anaphylactic prophylaxis, a large cyst measuring $10 \times 9 \times 9 \mathrm{~cm}$ was found replacing segments VI, VII, and VIII of the right lobe of the liver without any evidence of adjoining cystic lesions. After isolating the field with surgical sponges dipped in hypertonic saline (20\% saline), the cyst cavity was opened up and about $1 \mathrm{l}$ of hydatid fluid was aspirated, followed by filling up the cavity with scolicidal agent for $20 \mathrm{~min}$ (povidone iodine 10\% solution). Daughter cysts were carefully evacuated along with floating membranes. Deroofing was done, followed by covering the cystic cavity with omentum to complete the capitonnage, after inspecting for any residual bile leak points with fresh white surgical sponges. An intracavitary wide bore tube drain was secured. On postoperative day four (POD 4), bile leak was noted which gradually increased to 150 $300 \mathrm{ml} /$ day and over the next 2 days mild icterus with passage of pale stools was also seen. There was mild elevation of the liver enzymes with serum bilirubin of $0.8 /$ 0.2 units (total and conjugated). In view of worsening cholangitis and abdominal distension, the child was taken up for re-exploration on POD 10 and no active bile leak sites could be identified in the cyst cavity. However, no per operative cholangiogram was performed. The cavity was bile tinged uniformly with tube drain in situ. The seepage sites were identified and repaired with prolene. Cyst cavity was packed with gel foam after omentoplasty. Post second surgery, due to persistent bilious drain output of 100-150 ml/day, a HIDA scan was done which suggested active bile leak from the proximal right hepatic duct and no evidence of bilioenteric drainage (Fig. 2a, b).

Child was re-explored on postoperative day 11. Cyst cavity was opened and lavage given (Fig. 1b). Roux en Y limb $40 \mathrm{~cm}$ distal to DJ flexure mobilized through the transverse mesocolon up to the porta and jejunocystic anastomosis (cystojejunostomy) done with vicryl 4-0 (interrupted) (Fig. 1c). Wide bore infant feeding tube was secured into the cavity (transjejunal) as an anastomotic stent along with an abdominal drain in the subdiaphragmatic space. Postoperatively, the child was kept on total parenteral nutrition and systemic octreotide. The drain output gradually decreased over next 10 days, and the child improved clinically with passage of normal colored stools. Oral feeds were gradually resumed. Repeat HIDA (Fig. 2c, d) scan suggested evidence of bile leak into the surgical cavity (cystojejunal cavity) with minimal drainage through the subdiaphragmatic drain. The child was discharged after removal of abdominal drain. The child is doing well under regular follow-up since last 2 years.

\section{Discussion}

Only a few cases of giant hydatid liver cysts (diameter 10 $\mathrm{cm}$ or more) have been reported so far in adult literature, which is more scarce in children [3]. Conservative measures like partial cystectomy with external drainage, omentoplasty, and capitonnage carry a high incidence of postoperative biliary leakage and recurrence [4], which are lesser with procedures like hepatectomy and pericystectomy at a cost of radical resection. In a retrospective analysis of 64 patients (mean age 35.6 years), Deo et al. demonstrated a significantly lesser postoperative bile 
a

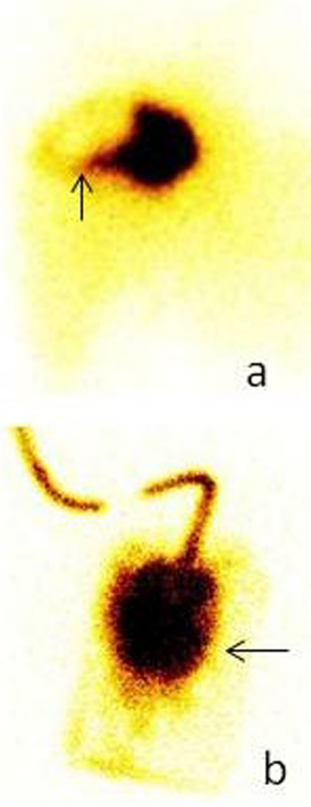

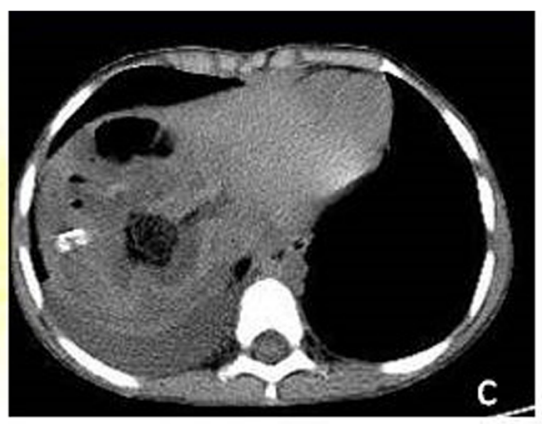

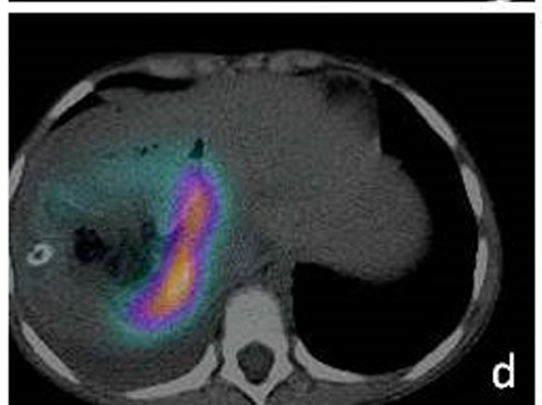

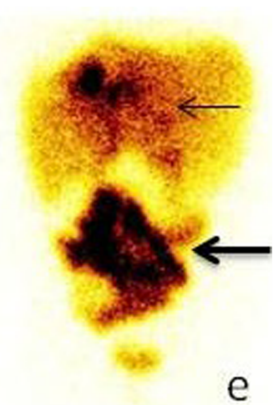

e

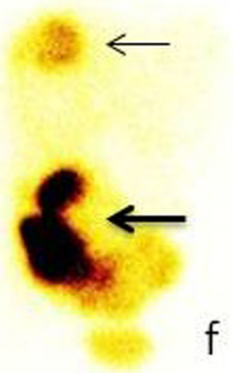

Fig. $2^{99 \mathrm{~m}}$ Tc-mebrofenin planar and SPECT/ CT scan (post second surgery): showing biliary leak from medial part of surgical cavity (segment VII/ VIII) and relatively photopenic area in right lobe (arrow), enlarged left lobe of the liver, preserved function and no evidence of bilio-enteric drainage (a), and subsequent collection of radiotracer in bag (arrow; b). Transverse CT and SPECT/CT images show collection of radiotracer in the surgical cavity $(\mathbf{c}, \mathbf{d})$. Follow-up scan shows hepatomegaly with preserved hepatocyte function, minimal tracer collection in surgical cavity (arrow), and patent bilio-enteric drainage without any duodenogastric reflux $(\mathbf{e}, \mathbf{f})$

leak and the need for endoscopic biliary stenting in radical surgery group [5]. In our case, we initially approached with omentoplasty and capitonnage with external tube drainage. However, persistent postoperative major bile fistula required re-exploration and drainage via cystojejunostomy. As per adult literature, biliary fistulas mostly close spontaneously; however, they may persist in $4-27.5 \%$ of cases [6]. Zeybeck et al. compared around 282 patients, who underwent treatment in the form of PAIR or surgery and suggested that postoperative bile drainage volume $<102 \mathrm{ml}$ is the only significant predictor of spontaneous closure [7]. To decrease the fistula output by providing low resistance bilio-enteric drainage, ERCP with endoscopic sphincterotomy has been tried successfully in adult biliary fistula persisting more than 3 weeks' duration or with output exceeding $300 \mathrm{ml} /$ day [1]. However, it requires general anesthesia and has not been reported in children due to technical difficulties.

Acar et al. have retrospectively compared the surgical procedures (partial cystectomy vs cystojejunostomy) in 28 patients (mean age 32.8 years) of giant hepatic hydatid cysts [8]. The cavity-related complications were found to be $25 \%$ with partial cystectomy as compared to none in cystojejunostomy. Yilmaz et al. have explained a prophylactic laparoscopic internal bilio-enteric drainage (Roux en Y cystojejunostomy) in an order to prevent long-term biliary fistulas in complicated hepatic hydatid cyst [9].

\section{Conclusion}

Giant hydatid cyst of the liver in pediatric population is extremely rare. Postoperative bile leaks are major comorbidities and should be treated conservatively wherever possible. Persistent major bile leak requiring ERCP with sphincterotomy can be managed successfully in children by internal drainage as Roux En Y cystojejunostomy.

\section{Abbreviations}

LFT: Liver function test; OPD: Outpatient department; CECT: Contrastenhanced computed tomography; PAC: Pre-anesthetic checkup; POD: Postoperative day; HIDA-Tc: Mebrofenin hepatobiliary scintigraphy; ERCP: Endoscopic retrograde cholangiopancreatography; PAIR: Punctureaspiration-injection-reaspiration

\section{Acknowledgements}

We are grateful to the patient and his parents who agreed to participate and gave consent for the publication.

\section{Authors' contributions}

SB drafted the manuscript and did the literature search. MB was the treating surgeon who conceptualized and finalized the manuscript. RPK did the critical revision. AS performed and interpreted the nuclear scans. RS supervised and did the critical revision. The authors have read and approved the manuscript of this case report.

\section{Funding \\ None}

Availability of data and materials Yes 


\section{Ethics approval and consent to participate}

Yes

\section{Consent for publication}

The parents of the child have given consent for publication of the child's intra-operative images and also for publishing the patient details.

\section{Competing interests}

None

\section{Author details}

${ }^{1}$ Department of Pediatric Surgery, Post Graduate Institute of Medical Education and Research (PGIMER), Sector 12, Chandigarh 160012, India. ${ }^{2}$ Department of Nuclear Medicine, Post Graduate Institute of Medical Education and Research (PGIMER), Chandigarh, India.

Received: 1 July 2020 Accepted: 20 October 2020

Published online: 10 December 2020

\section{References}

1. Dolay K, Akbulut S. Role of endoscopic retrograde

cholangiopancreatography in the management of hepatic hydatid disease. World J Gastroenterol. 2014;20(41):15253-61.

2. Ozaslan E, Bayraktar Y. Endoscopic therapy in the management of hepatobiliary hydatid disease. J Clin Gastroenterol. 2002;35(2):160-74.

3. Goyal VD, Sood S, Rana S, Pahwa S. Single-stage management of large pulmonary and hepatic hydatid cysts in pediatric age group: report of two cases. Lung India. 2014;31(3):267-9.

4. Kayaalp C, Sengul N, Akoglu M. Importance of cyst content in hydatid liver surgery. Arch Surg. 2002;137(2):159-63.

5. Deo KB, Kumar R, Tiwari G, Kumar H, Verma GR, Singh H. Surgical management of hepatic hydatid cysts - conservative versus radical surgery [published online ahead of print, 2020 Mar 27]. HPB (Oxford). 2020;S1365$182 X(20) 30082$.

6. Skroubis G, Vagianos C, Polydorou A, Tzoracoleftherakis E, Androulakis J. Significance of bile leaks complicating conservative surgery for liver hydatidosis. World J Surg. 2002;26(6):704-8.

7. Zeybek N, Dede $H$, Balci D, et al. Biliary fistula after treatment for hydatid disease of the liver: when to intervene. World J Gastroenterol. 2013;19(3): 355-61

8. Acar F, Sahin M, Alptekin H, Yılmaz H, Kafalı ME. Surgical treatment of giant liver hydatid cysts: comparison of cystojejunostomy and partial cystectomy. Surg Today. 2014;44(11):2065-71.

9. Yilmaz H, Sahin M, Ece I, Yormaz S, Alptekin H. A new approach to the complicated liver hydatid cyst--laparoscopic Roux-en-Y cystojejunostomy. Prague Med Rep. 2015;116(3):233-8.

\section{Publisher's Note}

Springer Nature remains neutral with regard to jurisdictional claims in published maps and institutional affiliations.

\section{Submit your manuscript to a SpringerOpen ${ }^{\circ}$ journal and benefit from:}

- Convenient online submission

- Rigorous peer review

- Open access: articles freely available online

- High visibility within the field

- Retaining the copyright to your article 